\title{
Greatly suppressed potential inhomogeneity and performance improvement of $c$-plane InGaN green laser diodes
}

\author{
Aiqin Tian ${ }^{1,2}$, Lei $\mathrm{Hu}^{1,2}$, Xuan $\mathrm{Li}^{1,2,3}$, Si Wu ${ }^{1,2}$, Peng Xu ${ }^{4}$, Dan Wang ${ }^{1,2}$, Renlin Zhou ${ }^{1,2,3}$, Binglei Guo \\ Fangzhi $\mathrm{Li}^{1,2,3}$, Wei Zhou ${ }^{1,2}$, Deyao $\mathrm{Li}^{1,2}$, Masao Ikeda ${ }^{1,2}$, Hui Yang ${ }^{1,2,3}$ and Jianping Liu ${ }^{1,2,3^{*}}$
}

High-performance green InGaN laser diodes (LDs) are highly demanded in laser display, medical instruments, and quantum technology [1-4]. However, the fabrication of green LDs is challenging, and GaN-based green LDs $(\lambda>500 \mathrm{~nm})$ were realized by Osram Corp until 2009 [5], which was 15 years after the first violet InGaN LDs. The greatest challenge is the growth of InGaN/(In)GaN multiple-quantum-well (MQW) active regions with high potential homogeneity. The potential fluctuation becomes pronounced as the indium composition increases in InGaN quantum wells (QWs) [6] due to the composition and interface fluctuation. The complex epitaxial structure of LDs results in a large strain and severe thermal degradation of InGaN during p-AlGaN growth $[7,8]$, therefore further deteriorating the potential homogeneity. The potential inhomogeneity suppresses the gain [9-11]. Additionally, potential inhomogeneity results in the reduced quantum efficiency in high-composition InGaN QWs [12,13].

In this letter, we report the optical characteristics of our green LD structure and chips. Greatly suppressed potential (luminescence) inhomogeneity is indicated first by temperature-dependent photoluminescence (TDPL) and time-resolved PL (TRPL) measurement of green LD structure and then by electroluminescence (EL) measurement of LD chips. The improved LD performance is shown as a result of greatly suppressed potential inhomogeneity in the InGaN QW active region.

Green LD structures were grown through a low-pressure metalorganic chemical vapor deposition reactor on $c$-plane freestanding $\mathrm{GaN}$ substrates. Trimethyl-aluminum, trimethylindium, and ammonia $\left(\mathrm{NH}_{3}\right)$ were used as the precursors for $\mathrm{Al}$, In, and $\mathrm{N}$, respectively. Triethyl-gallium was used as the precursor for $\mathrm{Ga}$ for InGaN layers and $\mathrm{GaN}$ quantum barrier layer, whereas trimethyl-gallium was the precursor for $\mathrm{Ga}$ for the other layers. Nitrogen and hydrogen were used as carrier gases. Monosilane $\left(\mathrm{SiH}_{4}\right)$ and bis(cyclopentadienyl)magnesium $\left(\mathrm{Cp}_{2} \mathrm{Mg}\right)$ were used as $\mathrm{n}$ - and $\mathrm{p}$-type dopants, respectively. The structure of green LDs comprised the following: a regrown nGaN layer, followed by an n-AlGaN cladding layer, an InGaN lower waveguide (WG) layer, two pairs of InGaN/GaN MQW active region, an upper InGaN (u-InGaN) WG layer, a p-AlGaN electron blocking layer, a $\mathrm{p}-\mathrm{AlGaN} / \mathrm{GaN}$ superlattice (SL) cladding layer, and a heavily doped $\mathrm{p}^{+}-\mathrm{GaN}$ contact layer. During the InGaN/GaN MQW growth, special attention was paid to obtain orderly step-flow growth and sharp interface [14-16]. The p-AlGaN/GaN SL cladding layer was grown at a low temperature of $900^{\circ} \mathrm{C}$ to suppress the degradation of the high Incontent InGaN/GaN MQW active region [8]. In addition, the relatively high pressure of $400 \mathrm{mbar}(1 \mathrm{mbar}=100 \mathrm{~Pa})$ was adopted to suppress the incorporation of carbon impurities and ensure the low resistivity of the low-temperature grown $\mathrm{p}$ $\mathrm{AlGaN} / \mathrm{GaN}$ SL cladding layer $[17,18]$. Indium tin oxide (ITO) was deposited as an additional cladding layer to further suppress the thermal degradation of green InGaN QWs [19]. Fig. 1 shows the schematic of the device structure, layer structure, and light distribution perpendicular to the $\mathrm{p}-\mathrm{n}$ junction of green LDs.

TDPL measurement was then performed on the green LD structure. The excitation power density was $7 \mathrm{~W} \mathrm{~cm}^{-2}$ using a $405-\mathrm{nm}$ diode laser. The measured temperature range was from $10 \mathrm{~K}$ to room temperature. Fig. 2a shows the TDPL full-widthhalf maximums (FWHMs) and PL peak energy of the green LD structure. The PL FWHMs at 10 and $300 \mathrm{~K}$ were 47 and $108 \mathrm{meV}$, respectively. To the best of our knowledge, this PL FWHM is the narrowest one ever reported. On the other hand, the TDPL peak energy showed an "S-shape," which is commonly observed for InGaN MQWs and indicates the existence of potential fluctuation in the InGaN MQW active region [20-23]. The widely used Varshni's empirical formula (Equation (1)), which was proposed by Eliseev [6], was used to quantify the degree of potential fluctuation [20-23].

$E_{\mathrm{g}}(T)=E_{\mathrm{g}}(0)-\left(\frac{\alpha T^{2}}{\beta+T}\right)-\frac{\sigma^{2}}{k_{\mathrm{B}} T}$,

where $E_{\mathrm{g}}(0)$ is the band-gap energy at $T=0 \mathrm{~K}, \alpha$ and $\beta$ are Varshni's thermal coefficients, $\sigma$ is the standard deviation of the energy distribution width of localized states, and $k_{\mathrm{B}}$ is the Boltzmann constant. The solid red lines in Fig. $2 \mathrm{a}$ are the fitting curves according to Equation (1). The parameters $\alpha$ and $\beta$ were set to $0.43 \mathrm{meV} \mathrm{K}^{-1}$ and $650 \mathrm{~K}$, respectively. The fitted $\sigma$ value, which indicates the degree of localization effect and broadening of the spectra, was $18.6 \mathrm{meV}$. This $\sigma$ value is notably smaller than that reported by Eliseev [6] for InGaN QW emitting in the green range and smaller than that reported for Nichia's green LD structure [20] (Fig. 2b). This result indicates that the homogeneity of our green LD structure has been greatly improved.

TRPL measurements were performed at $12 \mathrm{~K}$ with the

\footnotetext{
${ }^{1}$ Suzhou Institute of Nano-tech and Nano-bionics, Chinese Academy of Sciences, Suzhou 215123, China

${ }^{2}$ Key Laboratory of Nanodevices and Applications, Chinese Academy of Sciences, Suzhou 215123, China

${ }^{3}$ School of Nano Technology and Nano Bionics, University of Science and Technology of China, Hefei 230026, China

${ }^{4}$ Guangdong (Foshan) Branch, Suzhou Institute of Nano-tech and Nano-bionics, Chinese Academy of Sciences, Foshan 528000, China

* Corresponding author (email: jpliu2010@sinano.ac.cn)
} 


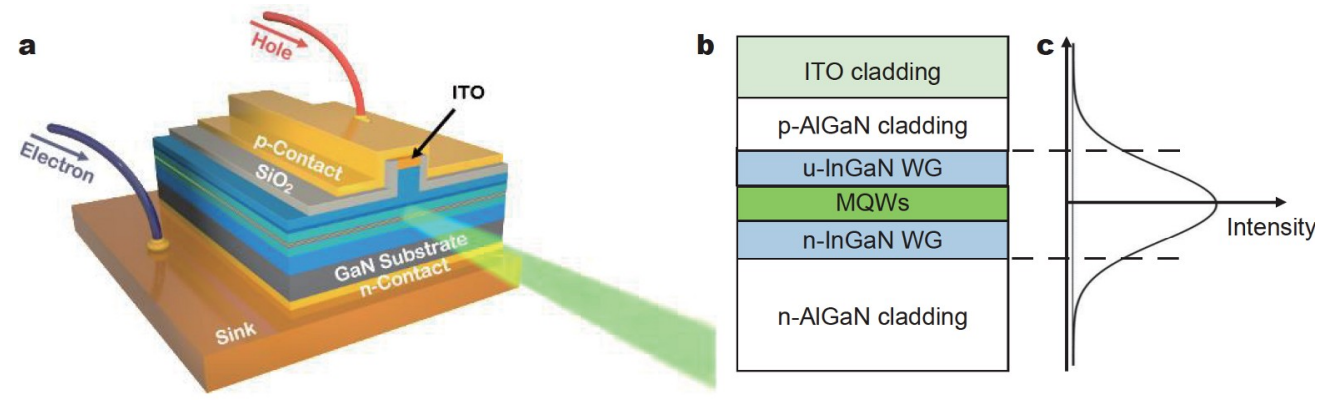

Figure 1 Schematic of the (a) device structure, (b) layer structure, and (c) light distribution perpendicular to the p-n junction of green LDs.
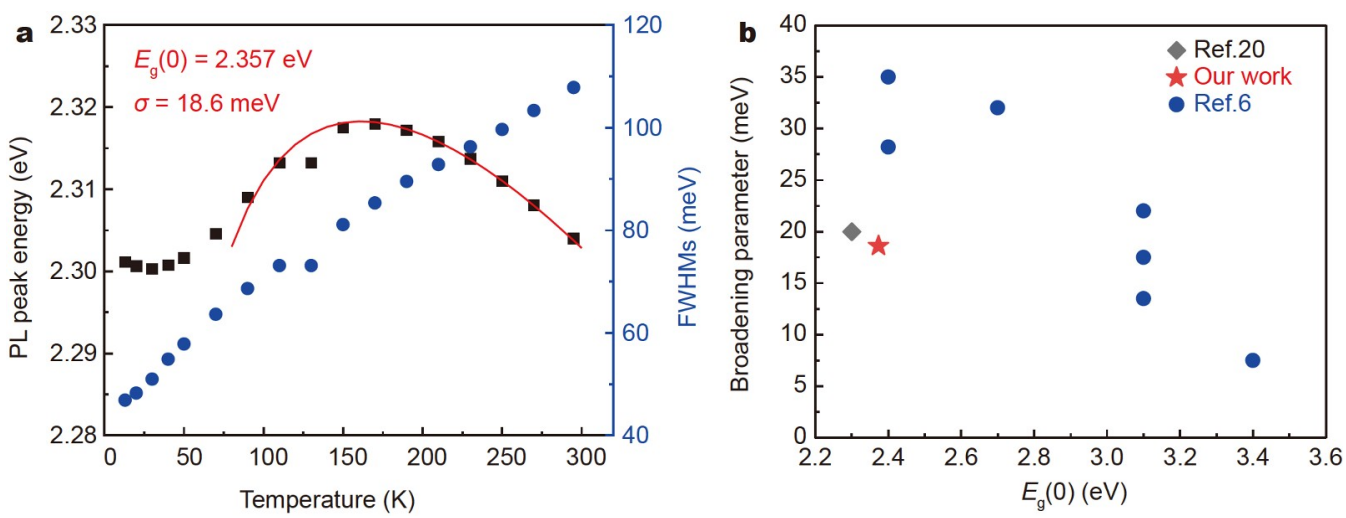

Figure 2 (a) TDPL peak energy and FWHMs of the green LD structure. (b) Broadening parameter of InGaN-based QWs or LD structure as a function of emission energy.

experimental setup we reported previously at an excitation power density of $3 \mathrm{~kW} \mathrm{~cm}^{-2}$ [24]. Fig. 3 shows the time-integrated PL spectrum and recombination lifetime of the green LD structure. The red squares indicate the measured recombination lifetime. At a low temperature of $12 \mathrm{~K}$, the recombination lifetimes are considered to be the radiative lifetime. According to a weakly localized exciton model [25], the emission energy (E) dependence of the PL lifetime $\tau$ can be expressed as Equation (2):

$\tau=\tau_{\text {rad }} /\left(1+\exp \left(\left(E-E_{\mathrm{me}}\right) / E_{0}\right)\right)$,

where $\tau_{\text {rad }}$ is the radiative lifetime, $E_{\mathrm{me}}$ is the mobility edge, and $E_{0}$ is the characteristic energy describing the tail state for exciton localization. The solid red curve in Fig. 3 is the fitted data obtained using this equation. The $\tau_{\text {rad }}, E_{\text {me }}$, and $E_{0}$ were $155 \mathrm{~ns}$, $2.35 \mathrm{eV}$, and $19 \mathrm{meV}$, respectively. The $E_{0}$ value is smaller than that reported for the state-of-the-art $c$-plane green LD structure [20] and comparable to that for the state-of-the-art semipolar green LD structure [26], indicating the excellent homogeneity in the active region of our LD structure.

Hybrid green LDs with an ITO cladding layer were fabricated with a ridge width of $15 \mu \mathrm{m}$ and a cavity length of $1200 \mu \mathrm{m}$ by conventional lithography and lift-off technique. The cavities were formed by cleaving along the $m$-plane facets. The EL measurements of the LD chips were carried out under pulsed operation at room temperature with a pulse width of $1 \mu$ s and a repetition frequency of $10 \mathrm{kHz}$ to minimize the self-heating effects. Fig. 4a shows the EL spectra of green LD at current densities of 0.02 and $0.15 \mathrm{kA} \mathrm{cm}^{-2}$ and the lasing spectrum at a threshold current density of $1.80 \mathrm{kA} \mathrm{cm}^{-2}$. The emission peaks

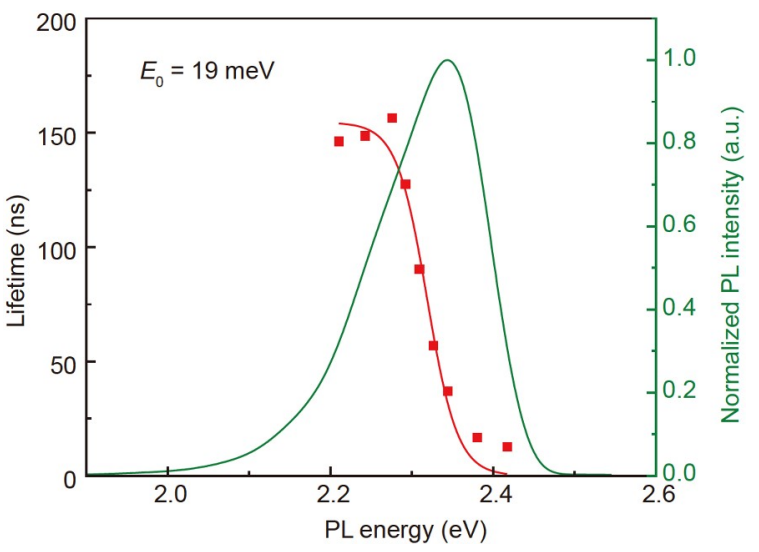

Figure 3 PL spectrum and energy dependence of PL lifetime of the green $\mathrm{LD}$ structure at $12 \mathrm{~K}$. The solid red line indicates the fit by the weak localization model.

showed a blue shift, which was caused by the screen of the polarization field as the carrier density in the QWs increased. The peak wavelengths at current densities of 0.02 and $0.15 \mathrm{kA} \mathrm{cm}^{-2}$ were 541.0 and $534.8 \mathrm{~nm}$, respectively. The lasing wavelength was $511.3 \mathrm{~nm}$. Fig. $4 \mathrm{~b}$ shows the output power of LD chips as a function of the injection current (power-current $(P-I)$ curve). The slope efficiency was $0.8 \mathrm{~W} \mathrm{~A}^{-1}$ up to $2 \mathrm{~A}$, and it decreased beyond $2 \mathrm{~A}$, which was possibly caused by the carrier leakage or gain saturation kicking in. The optical power was $1.7 \mathrm{~W}$ at an injection current of $3 \mathrm{~A}$.

Fig. 5a presents the EL FWHMs of the above-mentioned LD, which were $27(114 \mathrm{meV})$ and $28 \mathrm{~nm}$, at current densities of 0.02 

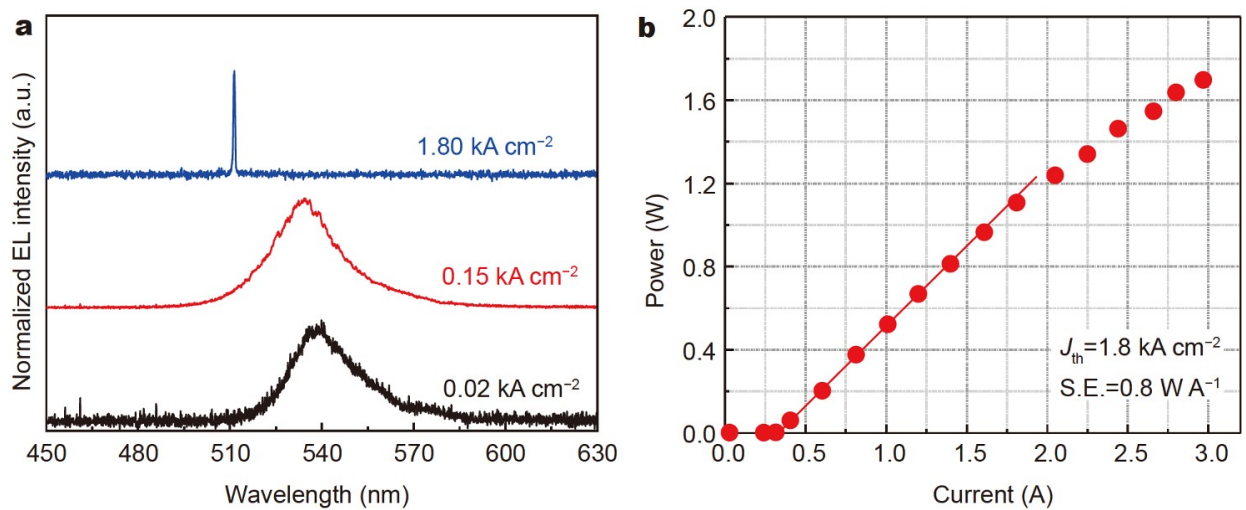

Figure 4 (a) EL spectra of the green LD at current densities of $0.02,0.15$, and $1.80 \mathrm{kA} \mathrm{cm}^{-2}$. (b) Output power of LD device as a function of current.
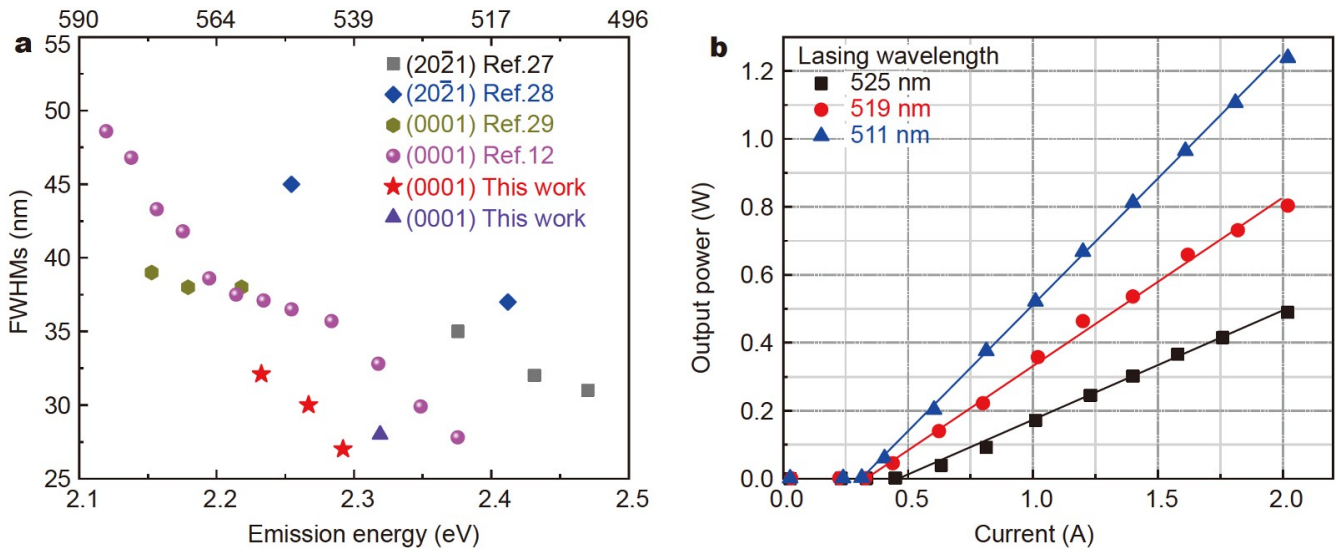

Figure 5 (a) EL FWHMs of InGaN-based LEDs or LDs as a function of emission energy. The data for comparison were from Refs [12,27-29]. The data from Ref. [27] are FWHMs at an injection current density of $0.15 \mathrm{kA} \mathrm{cm}^{-2}$. The data from Ref. [29] are FWHMs at an injection current density of $0.09 \mathrm{kA} \mathrm{cm}^{-2}$. The data from Ref. [28,12] are FWHMs at an injection current density of $0.02 \mathrm{kA} \mathrm{cm}^{-2}$. The data from this work are FWHMs at injection current densities of $0.02 \mathrm{kA} \mathrm{cm}^{-2}$ (red pentagram) and $0.15 \mathrm{kA} \mathrm{cm}^{-2}$ (purple triangle). (b) $P-I$ curves of green LDs with different lasing wavelengths.

and $0.15 \mathrm{kA} \mathrm{cm}^{-2}$, respectively. The EL FWHMs of the other two LDs with spontaneous emission wavelengths of 547.0 and $555.4 \mathrm{~nm}$ at a current density of $0.02 \mathrm{kA} \mathrm{cm}^{-2}$ were also plotted. The EL FWHMs of polar or semipolar InGaN-based lightemitting diodes (LEDs) or LDs reported in the literature are presented for comparison [12,27-29]. The FWHM values again indicate the degree of potential homogeneity. The FWHMs increased as a function of emission energy, regardless of the manufacturer, indicating that the homogeneity in InGaN QW worsened as the In content increased. The FWHMs of our LDs were the narrowest, indicating homogeneous luminescence in the active regions, which was consistent with the measurements discussed above. The lasing wavelengths of the other two LDs were 519.0 and $524.9 \mathrm{~nm}$. Fig. $5 \mathrm{~b}$ shows the $P-I$ curves of the LDs with different lasing wavelengths. The output power decreased with the increase of lasing wavelength due to the increased threshold current and reduced slope efficiency, which was attributed to the poorer homogeneity obtained as the In content in the QWs increased.

In conclusion, green LD structure and LD chips were characterized by various optical measurements. The PL FWHM at $300 \mathrm{~K}$ under excitation power density of $7 \mathrm{~W} \mathrm{~cm}^{-2}$ was $108 \mathrm{meV}$, and the EL FWHM at a current density of $20 \mathrm{~A} \mathrm{~cm}^{-2}$ was $27 \mathrm{~nm}$ $(114 \mathrm{meV})$. Both results indicate a considerable improvement in potential homogeneity. The high potential homogeneity was also indicated by an extremely low $\sigma$ value describing the energy distribution width of the localized states obtained by TDPL and a very low $E_{0}$ value describing the tail state for exciton localization obtained by TRPL. As a result of the remarkable improvement of potential homogeneity, green LD chips with a slope efficiency of $0.8 \mathrm{~W} \mathrm{~A}^{-1}$ and an output power of $1.7 \mathrm{~W}$ have been achieved.

Received 5 August 2021; accepted 18 September 2021; published online 12 November 2021

1 Ohta H, DenBaars SP, Nakamura S. Future of group-III nitride semiconductor green laser diodes. J Opt Soc Am B, 2010, 27: B45

2 Lingrong J, Jianping L, Aiqin T, et al. GaN-based green laser diodes. J Semicond, 2016, 37: 111001

3 Tian A, Hu L, Zhang L, et al. Design and growth of GaN-based blue and green laser diodes. Sci China Mater, 2020, 63: 1348-1363

4 Risk WP, Gosnell TR, Nurmikko AV. Compact Blue-Green Lasers. Cambridge, New York: Cambridge University Press, 2003.

5 Queren D, Avramescu A, Brüderl G, et al. $500 \mathrm{~nm}$ electrically driven InGaN based laser diodes. Appl Phys Lett, 2009, 94: 081119

6 Eliseev PG. The red $\sigma^{2} / k T$ spectral shift in partially disordered semiconductors. J Appl Phys, 2003, 93: 5404-5415

7 Strauß U, Avramescu A, Lermer T, et al. Pros and cons of green InGaN laser on c-plane GaN. Phys Status Solidi B, 2011, 248: 652-657 
8 Li Z, Liu J, Feng M, et al. Suppression of thermal degradation of InGaN/GaN quantum wells in green laser diode structures during the epitaxial growth. Appl Phys Lett, 2013, 103: 152109

9 Kojima K, Funato M, Kawakami Y, et al. Gain suppression phenomena observed in $\operatorname{In}_{x} \mathrm{Ga}_{1-x} \mathrm{~N}$ quantum well laser diodes emitting at $470 \mathrm{~nm}$. Appl Phys Lett, 2006, 89: 241127

10 Kojima K, Schwarz UT, Funato M, et al. Optical gain spectra for near UV to aquamarine (Al,In) GaN laser diodes. Opt Express, 2007, 15: 7730-7736

11 Liang Y, Liu J, Ikeda $\mathrm{M}$, et al. Effect of inhomogeneous broadening on threshold current of GaN-based green laser diodes. J Semicond, 2019, 40: 052802

12 Jiang $\mathrm{F}$, Zhang $\mathrm{J}$, Xu L, et al. Efficient InGaN-based yellow-lightemitting diodes. Photon Res, 2019, 7: 144-148

13 Zhang S, Zhang J, Gao J, et al. Efficient emission of InGaN-based lightemitting diodes: Toward orange and red. Photon Res, 2020, 8: 16711675

14 Zhou K, Liu J, Ikeda M, et al. Influence of substrate surface defects on the homoepitaxial growth of $\mathrm{GaN}$ (0001) by metalorganic vapor phase epitaxy. J Cryst Growth, 2015, 416: 175-181

15 Tian A, Liu J, Zhang L, et al. Significant increase of quantum efficiency of green InGaN quantum well by realizing step-flow growth. Appl Phys Lett, 2017, 111: 112102

16 Tian A, Liu J, Zhang L, et al. Green laser diodes with low threshold current density via interface engineering of InGaN/GaN quantum well active region. Opt Express, 2017, 25: 415

17 Tian A, Liu J, Ikeda M, et al. Conductivity enhancement in AlGaN:Mg by suppressing the incorporation of carbon impurity. Appl Phys Express, 2015, 8: 051001

18 Tian A, Liu J, Zhang L, et al. Green laser diodes with low operation voltage obtained by suppressing carbon impurity in AlGaN:Mg cladding layer. Phys Status Solidi C, 2016, 13: 245-247

19 Hu L, Ren X, Liu J, et al. High-power hybrid GaN-based green laser diodes with ITO cladding layer. Photon Res, 2020, 8: 279

20 Funato M, Kim YS, Hira T, et al. Remarkably suppressed luminescence inhomogeneity in a (0001) InGaN green laser structure. Appl Phys Express, 2013, 6: 111002

21 Tian A, Liu J, Zhang L, et al. Optical characterization of InGaN/GaN quantum well active region of green laser diodes. Appl Phys Express, 2017, 10: 012701

22 Zhu L, Liu B. Optical properties studies in InGaN/GaN multiplequantum well. Solid-State Electron, 2009, 53: 336-340

23 Langer T, Pietscher HG, Ketzer FA, et al. S shape in polar GaInN/GaN quantum wells: Piezoelectric-field-induced blue shift driven by onset of nonradiative recombination. Phys Rev B, 2014, 90: 205302

24 Zhou R, Ikeda M, Zhang F, et al. Steady-state recombination lifetimes in polar InGaN/GaN quantum wells by time-resolved photoluminescence. Jpn J Appl Phys, 2019, 58: SCCB07

25 Gourdon C, Lavallard P. Exciton transfer between localized states in $\mathrm{CdS}_{1-x} \mathrm{Se}_{x}$ alloys. Phys Stat Sol (B), 1989, 153: 641-652

26 Funato M, Kaneta A, Kawakami Y, et al. Weak carrier/exciton localization in InGaN quantum wells for green laser diodes fabricated on semi-polar $\{20 \overline{2} 1\} \mathrm{GaN}$ substrates. Appl Phys Express, 2010, 3: 021002

27 Enya Y, Yoshizumi Y, Kyono T, et al. $531 \mathrm{~nm}$ green lasing of InGaN based laser diodes on semi-polar $\{20 \overline{2} 1\}$ free-standing GaN substrates. Appl Phys Express, 2009, 2: 082101

28 Yamamoto S, Zhao Y, Pan CC, et al. High-efficiency single-quantumwell green and yellow-green light-emitting diodes on semipolar $\{20 \overline{2} 1\}$ GaN substrates. Appl Phys Express, 2010, 3: 122102

29 Saito S, Hashimoto R, Hwang J, et al. InGaN light-emitting diodes on $c$ face sapphire substrates in green gap spectral range. Appl Phys Express, 2013, 6: 111004

Acknowledgements This work was financially supported by the National Key Research and Development Program of China (2017YFE0131500), the National Natural Science Foundation of China (61834008, 61704184 and 61804164), the Key Research and Development Program of Jiangsu province (BE2020004), the Natural Science Foundation of Jiangsu Province
(BK20180254), and Guangdong Basic and Applied Basic Research Foundation (2019B1515120091).

Author contributions Liu J directed all the work in this manuscript, proposed the topic and outline of the manuscript. Tian A wrote the manuscript under the direction of Liu J. All authors contributed to the discussion of the manuscript.

Conflict of interest The authors declare that they have no conflict of interest.

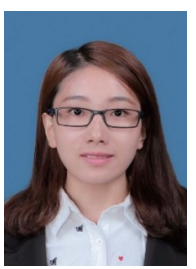

Aiqin Tian is an associate researcher at Suzhou Institute of Nano-Tech and Nano-Bionics, Chinese Academy of Sciences. She earned her doctoral degree from the University of Chinese Academy of Sciences in 2017. Her research focuses on the metal-organic chemical vapor deposition (MOCVD) growth of III-nitride materials and devices.

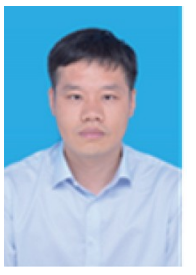

Jianping Liu is a professor at Suzhou Institute of NanoTech and Nano-Bionics, Chinese Academy of Sciences. He earned his doctoral degree from the Institute of Semiconductors, Chinese Academy of Sciences, in 2004. He worked at the Laboratory of Optoelectronics Technology at Beijing University of Technology from 2004 to 2006 . He did postdoctoral research in the Department of Electrical Engineering at Georgia Institute of Technology from 2006 to 2010. His research interests include GaN-based materials and optoelectronic devices.

\section{改善势能均匀性提升 $\boldsymbol{c}$ 面InGaN绿光激光器性能}

田爱琴 ${ }^{1,2}$, 胡否 ${ }^{1,2}$, 李暄 $1,2,3$, 吴思 ${ }^{1,2}$, 徐鹏 ${ }^{4}$, 王旦 ${ }^{1,2}$, 周韧林 ${ }^{1,2,3}$, 郭炳否 ${ }^{4}$, 李方直 ${ }^{1,2,3}$, 周伟 ${ }^{1,2}$, 李德尧 ${ }^{1,2}$, 池田昌夫 夫 $^{1,2}$ 杨辉 ${ }^{1,2,3}$, 刘建平 $1,2,3^{*}$

摘要 激光显示、医疗设备及量子通信迫切需求高性能 $\mathrm{GaN}$ 基绿光激 光二极管 $(\mathrm{LD})$. 研制绿光 $\mathrm{LD}$ 最大的挑战是生长高势能均匀性的 $\mathrm{InGaN} /$ GaN多量子阱. 我们采用各种光学测量手段对绿光 $L D$ 结构和芯片进行 了表征. 在激发功率密度为 $7 \mathrm{~W} \mathrm{~cm}^{-2}$ 时, $300 \mathrm{~K}$ 下光致发光半高宽为 $108 \mathrm{meV}$, 电流密度为 $20 \mathrm{~A} \mathrm{~cm}^{-2}$ 时, 电致发光半高宽为 $114 \mathrm{meV}$, 这些研 究结果表明势能均匀性得到了显著改善. 同时, 由变温光致发光测试得 到的表征局域态分布宽度的 $\sigma$ 值和由时间分辨光致发光测试得到的表 征激子局域带尾态的 $E_{0}$ 值都很小, 进一步表明势能均匀性很好. 由于势 能均匀性的极大改善, 实现了斜率效率 $0.8 \mathrm{~W} \mathrm{~A}^{-1}$, 输出光功率可以达到 $1.7 \mathrm{~W}$ 的绿光LD芯片. 